(as in chemistry, for the increasing oxidation results, \&c.), the coinage of words as fresh needs arose would proceed automatically on rational lines.

This might very weil form the object of a special committee of the British Association.

Mr. Oliver Heaviside's system for electromagnetic matters has much to recommend itself for adoption, also, in general physics.

For example, after the plan (1) conduction, (2) conductance, (3) conductivity, we would have, in the case of radiant energy, (I) radiation, (2) radiatance, (3) radiativity.

The first is for reference in a general way to the phenomenon in question; the second refers to its amount in appropriate units in any individual case; while the third is suitable for expressing the peculiar action or factor in the phenomenon possessed by different kinds of bodies. Thus the radiatance from a hot kettle would be the total quantity of energy lost per second. The radiativity would be the quantity of this per square centimetre.

With a view of examining the feasibility of this system, the following list is subjoined. Many of the words appear at first as if they would prove most awkward in practice, but remembering similar fears (which subsequently proved groundless) in electromagnetic matters, one is afraid to say they are due to more than unfamiliarity.

\begin{tabular}{l|l|l}
\hline Phenomenon & Amount of & Coefficient of \\
\cline { 1 - 2 } Absorption & Absorbance & Absorbivity \\
Attrition & Attritance & Attritivity \\
Diffusion & Diffusance & Diffusivity \\
Emission & Emissance & Emissivity \\
Expansion & Expansance & Expansivity \\
Extension & Extensance & Extensivity \\
Friction & Frictance & Frictivity \\
Gravitation & Gravitance & Gravitivity \\
Ieat & Heatance & Heativity \\
Inertia & Inertance & Inertivity \\
Polarization & Polarizance & Polarizivity \\
Reflection & Reflectance & Reflectivity \\
Refraction & Refractance & Refractivity \\
Rotation & Rotatance & Rotativity \\
Solution & Solutance & Solutivity \\
& & \\
\hline
\end{tabular}

Special attention deserves to be called to inertance as a goud name for mass, and inertivity for density, to rotatance lor moment of momentum, and rotativity for moment of inertia. Geo. Fras. Fitzgerald, Fred, T. Trouton.

Physical Laboratory, Trinity College, Dublin, December 5 .

\section{On the Nomenclature for Radiant Energy.}

In connection with this subject there are many things to be considered, and one of the most important is the question of radiation and absorption, which requires a completely new nomenclature to get over very serious ambiguities that at present embarrass the subject. It is very necessary to distinguish between what may be called, on Prevost's theory of exchanges, the total radiatance from the actually observed loss of energy by radiation which is, according to this theory, the difference between the total radiatance and the total absorbance. This difference per degree of temperature is very commonly called the radiating power, but this same word is used in quite a different sense when it is attempted to prove, from Prevost's theory of exchanges, that the radiating is equal to the absorbing powers by a consideration of thermal equilibrium. In this latter case the term radiating power means obviously the total radiatance of Prevost's theory.

It may also be worth while calling attention to the theory, given at Nottingham by Lord Rayleigh, as to the absorbivity of lough surfaces being equal to unity. The yeneral idea underlying his investigation is that owing to diffraction the waves amongst the deep corrugations in the surface spread abroad within them, and hardly any of their energy escapes out again. At the time I called his attention to the way a similar theory would explain the radiating power of rough surfaces, as I have taught here for years back. I am mentioning this now to call attention to an experiment of Magnus' mentioned in Jamin ("Cours de Physique," vol. iii. part 3, p. I 13, top line, edition I88I ; Pogg. Ann. vol. cxxiv. p. 476), where I have an old note concerning this theory, and which I had forgotten, to the effect that the radiation from platinised platinum was much greater than that from smooth platinum, but that the increase was chiefly in the ultra-red rays, for that the difference between the two plates was almost completely annulled by a plate of alum. This is what would be expected from the above theory, because corrugations that are small enough to affect the ultra-red radiations might still be too large to be anything but a smooth surface for the visible radiations. There is evidently a good deal still to be done on radiativity. Geo. Fras. Fitzgerald.

Physical Laboratory, Trinity College, Dublin,

December 5 .

\section{Flame.}

I TRUST that, in common with other readers of NATURE, I feel duly chastened by the homily which Dr. Armstrong has addressed to you on the subject of my lecture on "Flame." It is perhaps well that we should be warned from time to time against the sin of dogmatising. The only objection I have to the process is that I should be singled out as a sinner without some good reason being given for the selection. I am charged with forgetting that certain alleged facts "are but phenomena interpreted by our own limited intelligence," and yet I actually wound up my lecture with a quotation from Carlyle, intended to emphasise that very point. If Dr. Armstrong had said that this was an "appeal to the gallery," I should not have complained.

I do not feel equal to the metaphysical discussion to which Dr. Armstrong opens the way. I know only of one kind of fact, namely, "phenomena interpreted by our own limited intelligence," and it seems better to spell the thing in four letters than to bury it in phrases that smack of the pulpit.

Now let us see what I have done. I found on burning a hydrocarbon with a limited supply of oxygen, that in the cooled products of combustion all the carbon was oxidised, and that some of the hydrogen was set free. I had been brought up, like Dr. Armstrong, to cherish certain chemical dogmas, one of which was that the hydrogen of a burning hydrocarbon was oxidised before the carbon. I now asked myself what were the grounds for this dogma? It seemed to me to spring from the narrowest view of things, probably from the fact-I mean the bylimited-intelligence-interpreted-phenomenon-that hydrogen gas is easier to set on fire than a lump of charcoal. This was obviously an unscientific conclusion, for the carbon of a burning hydr... carbon is part of a gas, and when it is oxidised it has not, like a lump of charcoal, to be virtually gasified in the act of burning, and so to demand a high temperature and an untold amount of heat. I then read with great profit a paper by Dr. Armstrong, which confirmed my opinion that the heat of combustion of an atom of gaseous carbon, in forming carbon monoxide, must be exceedingly high, and so on all grounds I concluded that there was no prima facie reason for assuming that the hydrogen of a hydrocarbon would be oxidised in preference to the carbon. Experiment showed the opposite result; the carbon was oxidised, and I adopted the straightforward explanation, and renounced the old dogma. There were alternative explanations. It was conceivable that the hydrogen burnt first and liberated the carbon, which then acted upon the steam to produce one or both of the oxides of carbon and free hydrogen. We should then have two successive chemical reactions. I pointed out that there was only one piece of indirect evidence in favour of this view, and that has since been contradicted by Prof. Dixon. But Dr. Armstrong appears to suggest the view that the two chemical reactions are simultaneous. Now we know of plenty of chen. ical reactions which are best understood and remembered if we represent them by two simulaneous equations. When, for instance, zinc is heated with strong sulphuric acid, and we do not get hydrogen, we may explain the apparent anomaly by saying that hydrogen is liberated, but that it immediately attacks some of the hot sulphuric acid, producing sulphur dioxide and water. Or we may choose another pair of "normal" reactions which, being supposed to happen simultaneously, will explain the " $a b$ normal " result. But surely no one thinks that the two reactions do proceed simultaneously. I use this method of exposition very largely, but I always tell my students that it is analogous to the treatment of forces in dynamics. We suppose 